\title{
Growing Prevalence and Incidence of Diabetes in Republic of Macedonia in the Past 5 Years Based on Data from the National System for Electronic Health Records
}

\author{
Irfan Ahmeti ${ }^{1,2,3 *}$, Iskra Bitovska ${ }^{1,2,3}$, Snezhana Markovic ${ }^{1,2,3}$, Elena Sukarova-Angelovska ${ }^{1,2,4}$, Sasha Jovanovska-Misevska ${ }^{1,3}$, \\ Goran Kocinski ${ }^{5}$ \\ ${ }^{1}$ University Clinic of Endocrinology, Diabetes and Metabolic Disorders, Skopje, Republic of Macedonia; ${ }^{2}$ National Committee \\ for Diabetes, Ministry of Health, Skopje, Republic of Macedonia; ${ }^{3}$ Medical Faculty, Ss Cyril and Methodius University of Skopje, \\ Skopje, Republic of Macedonia; ${ }^{4}$ University Clinic of Pediatric, Skopje, Republic of Macedonia; ${ }^{5}$ e-Health Directorate - Skopje, \\ Ministry of Health, Skopje, Republic of Macedonia
}

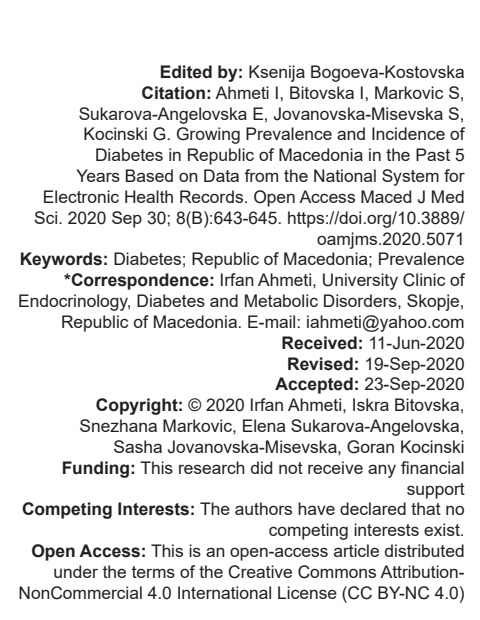

\begin{abstract}
BACKGROUND: Diabetes is a chronic metabolic disease characterized with a rapid progression of prevalence in the past three decades, especially in countries with low- and middle-income. Next three decades, this number of diabetes in the world is expected to be doubled. Early diagnosis and appropriate management of diabetes are the primary way to prevent and delay cardiovascular complications.

AIM: The aim of this study was to estimate the prevalence of diabetes in Republic of Macedonia, analyzing increasing trends in the past 5 years.

PATIENTS AND METHODS: In this retrospective study, we used the data from National electronic system e-health which was performed in late 2014 , which gives us nearly precise data, and we made statistical analysis for diabetes in the past 5 years (2015-2019).

RESULTS: In 2015, we have registered 103,480 patients with DM, in 2016, 108,130 patients, in 2017 114,408, in $2018,119,999$, and, in $2019,124,450$ patients with DM. About $95 \%$ of patients are with T2DM and $4,1 \%$ with T1DM. According the data from state statistical office for population of Republic of Macedonia, the prevalence of T2DM for the years $2015-2019$ is as follows: $5,66 \%$ in $2015,6.13 \%$ in $2016,6.55 \%$ in $2017,7,06 \%$ in 2018 , and $7,2 \%$ in 2019 . CONCLUSIONS: The number of registered patients with diabetes in the past 5 years has grown up for 20970 or $20 \%$, in the past 5 years the number of patients with type 2 diabetes has grown up for 18272 patients or $11 \%$. The prevalence of T2DM has increased for $1.54 \%$. Involvement of primary health care professionals has improved the early diagnosis of type 2 diabetes.
\end{abstract}

\section{Introduction}

Diabetes is a chronic metabolic disease characterized with a rapid progression of prevalence in the past three decades, especially in countries with lowand middle-income. The number of the patients with diabetes is expected to be doubled within the next three decades. Early diagnosis and appropriate management of diabetes are the primary way to prevent and delay CV complications. Together with population growth and ageing, this rise has led to a near quadrupling of the number of adults with diabetes worldwide [1]. For T2DM, which accounts for approximately $90 \%$ of the total, this rising trend can be attributed to ageing, a rapid increase in urbanization, and obesogenic environments. Incidence rates of T1D are also rising, contributing to the increase in diabetes prevalence. An additional contributor to the increased prevalence is better survival (in some populations) of people with diabetes through early detection, improved management of diabetes, and, consequently reduction in premature mortality [2]. Finally, the increasing number of younger adults with T2D in the recent years also contributes to the increase in overall T2D prevalence, through their longer survival.

Three in four people living with diabetes (352 million people - 72\%) are of working age (i.e., between 20 and 64 years). This number is expected to increase to 417 million by 2030 and to 486 million by 2045 . The prevalence of diabetes in adults (age 20-79 years) in the world is $8.3 \%$ and differs by continents and countries. In general, high income countries have higher prevalence $(10,4 \%)$, and low-income countries have lower prevalence $(4,0 \%)$ [3]. Republic of Macedonia is an upper-middleincome country that has made great strides in reforming its economy over the past decade. As a part of this group it is estimated to have diabetes age adjusted comparative prevalence 9,3\% [3], [4]. Until 2014, in our country, the prevalence of diabetes was as prediction number because of lack of national register for diabetes. As National 
electronic system, e-health was performed in late 2014, which gives us nearly precise data; we can more precisely calculate the prevalence and incidence of diabetes.

The aim of this study was to estimate the prevalence of diabetes in Republic of Macedonia, analyzing increasing trends in the past 5 years.

\section{Patients and Methods}

This is retrospective study the data from the National System for Electronic Health Records - "Moj Termin" was used to calculate the prevalence and incidence of diabetes. We analyzed statistical national data for type 1 diabetes and type 2 diabetes for the period of 5 years, from 2015 to 2019 . The data were collected from all levels of diabetes care (primary, secondary, and tertiary health care). We calculated the prevalence, incidence, and increasing rate of T1DM and T2DM for 5 years.

\section{Results}

The total number of registered patients with DM in 2015 was 103,480 , in 2016108,130 patients, in 2017 114,408, in 2018 119,999, and in 2019124,450 patients. Of them, 95\% had T2DM and 4,1\% T1DM (Figure 1). The others $(0.9 \%)$ had gestational diabetes or secondary diabetes.

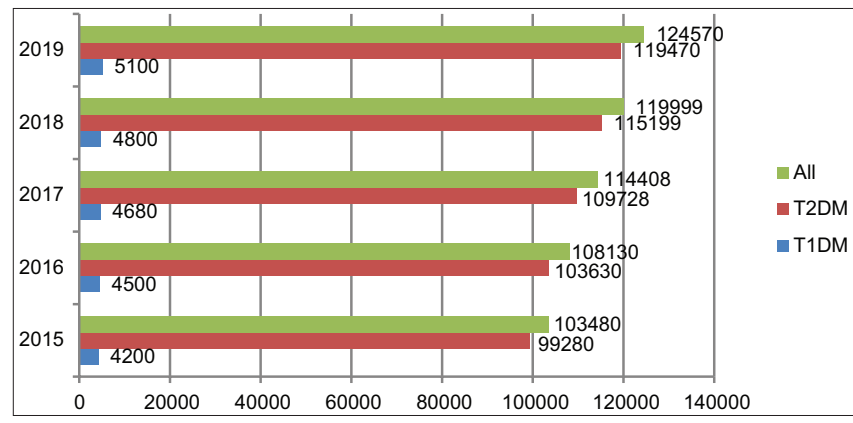

Figure 1: Number of patients with diabetes from 2015 to 2019 in R.N.M

Regarding the age, the most of Type 2 diabetes patients are of the age 20-79 years: In 2015, 99.52\%, and, in 2019, 99.35\% (Figure 2).

Based on the data from state statistical office for population of Republic of Macedonia (R.N.M.) (2083380), the prevalence of T2DM for the years 20152019 is as follows: $4.97 \%$ in $2015,5.19 \%$ in 2016 , $5.49 \%$ in $2017,5.76 \%$ in 2018 , and $6.12 \%$ in 2019 . The age-adjusted comparative prevalence of diabetes for the age $20-79$ year in a population $1,566,600$ of the age $20-79$ years is: In $20156.09 \%$, in $20166.49 \%$, in 2017 is

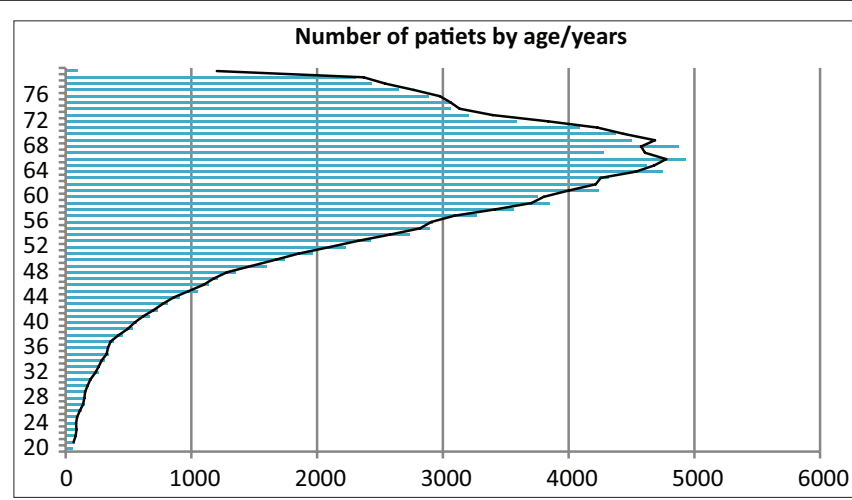

Figure 2: Distribution of patients by age from 20 to 79 years in 2019

$6.98 \%$, in 2018 is $7,3 \%$, and $7.6 \%$ in 2019 . The annual incidence was $4.2 \%$ in $2016,5.8 \%$ in $2017,4.88 \%$ in 2018 , and 3.71 in 2019 . The past 5 years, the number of people with diabetes in Republic of Macedonia is increased for 20\% (20264 patients).

The past 5 years diabetes is increasing in children (0-14 years) and adolescents (15-19 years) (Table 1) with the increasing of incidence in the past 2 years. The incidence for T1DM for age 0-14 years in

Table 1: The number of patients with diabetes by age

\begin{tabular}{llllll}
\hline Prevalence & 2015 & 2016 & 2017 & 2018 & 2019 \\
\hline T1DM 0-14 years & 156 & 192 & 227 & 272 & 312 \\
T1DM 15-19 years & 178 & 181 & 195 & 211 & 263 \\
Total T1 DM 0-19 years & 334 & 373 & 422 & 483 & 575 \\
T2DM 0-14 years & 28 & 39 & 54 & 64 & 76 \\
T2DM 15-19 years & 99 & 97 & 114 & 129 & 134 \\
Total DM 0-19 years & 461 & 509 & 590 & 676 & 785 \\
T1DM 20-79 & 3780 & 3990 & 4210 & 4289 & 4500 \\
T2 DM 20-79 & 91,772 & 97,790 & 105,205 & 110,346 & 114,550 \\
Total DM 20-79 years & 95,552 & 101,780 & 109,415 & 114,635 & 119,050 \\
\hline
\end{tabular}

last 5 years is: In 2015, 0.9\%, in 2016, $0.82 \%$, in 2017 , $0.75 \%$, in 2018, 0.94\%, and in 2019, $0.78 \%$.

According the working group, $56.1 \%$ of patients with diabetes are of age 25-65 years (Figure 3).

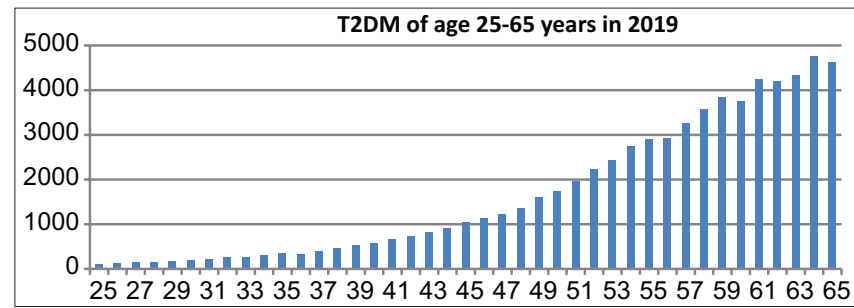

Figure 3: Distribution by productivity age of diabetes in 2019

According the treatment regime of diabetes, on insulin treatment 45,000 (36.16\%). From them, 59\% are on insulin analogues and $41 \%$ on human insulin therapy (Figure 4).

\section{Discussion}

Diabetes prevalence is increasing worldwide in the past three decades, especially in the countries 


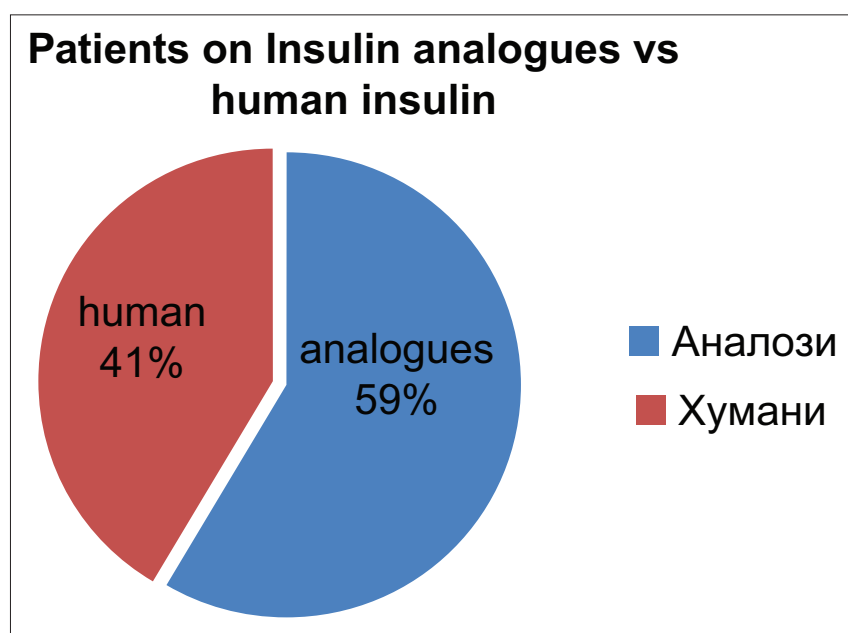

Figure 4: Insulin therapy in 2019 (analogs vs. human insulin)

\section{Conclusion}

The number of registered patients with diabetes in the past 5 years has increased cumulatively for 20,264 or $20 \%$, in the past 5 years, the number of patients with type 2 diabetes has increased cumulatively for 18,272 patients or $11 \%$. The prevalence of T2DM has increased for $1.54 \%$. Age- adjusted comparative prevalence of diabetes for the age 20-79 year has increased for $1.65 \%$. Involvement of primary healthcare professionals has improved the early diagnosis of type 2 diabetes. The electronic system of gathering data of patients is powerful tool for prompt statistical analysis, also gives opportunity for establishing the National registry of DM in future.

\section{References}

of diabetes in adults (age 20-79 years) in the world is $8.3 \%$. By continents, Europe has lower age adjusted comparative prevalence (6.3\%) [3]. Republic of Macedonia, as European country according the projections, has been expected to have age adjusted comparative prevalence $9.3 \%$, our result shows that age-adjusted comparative prevalence of diabetes for the age $20-79$ year is $7.6 \%$ in 2019 .

According the data from the IDF, Europe, North America, and Caribbean regions have the largest number of children with type 1 diabetes [5]. In the world, the number of children and adolescents (0-19 years) is $0.2 \%$. It is estimated that the incidence of type 1 diabetes among children and adolescents is increasing in many countries particularly in those aged $<15$ years [6]. The overall annual increase is estimated to be around $3 \%$ with strong indications of geographic differences; the slow increase of incidence of T1DM in this age in our country $(0.75-0.9 \%)$ is higher than the world but less than European average. Type 2 diabetes in children has increased in frequency around the world over the past two decades of the age 0-19 years and should be the focus of early intervention in the prevention program such as healthy diet and physical activities due to increase of body mass index in this group of population [7], [8].

The percentage of affected persons with diabetes of the working age $25-65$ years is $56,1 \%$. Comparing with world data, $72 \%$ of people with diabetes are in the working age of $20-64$ years [3].
1. NCD Risk Factor Collaboration (NCD-RisC). Worldwide trends in diabetes since 1980: A pooled analysis of 751 population-based studies with 4.4 million participants. Lancet. 2016;387(10027):1513-30. PMid:27061677

2. Chatterjee S, Khunti K, Davies MJ. Type 2 diabetes. Lancet. 2017;389(10085):2239-51. https://doi.org/10.1016/ s0140-6736(17)30058-2 PMid:28190580

3. International Diabetes Federation. IDF Diabetes Atlas. $9^{\text {th }}$ ed. Brussels, Belgium: International Diabetes Federation; 2019.

4. Available from: https://www.worldbank.org/en/country/ northmacedonia. [Last accessed 2020 May 01].

5. International Diabetes Federation. IDF Diabetes Atlas. $8^{\text {th }}$ ed Brussels, Belgium: International Diabetes Federation; 2017. Available from: http://www.diabetesatlas.org. [Last accessed 2020 May 01].

6. Cardwell CR, Stene LC, Joner G, Bulsara MK, Cinek O Rosenbauer $\mathrm{J}$, et al. Maternal age at birth and childhood Type 1 diabetes: A pooled analysis of 30 observational studies. Diabetes. 2010;59(2):486-94. https://doi.org/10.2337/db09-1166 PMid: 19875616

7. Nadeau K, Dabelea D. Epidemiology of Type 2 diabetes in children and adolescents. Endocr Res. 2008;33:35-58. https:// doi.org/10.1080/07435800802080138 PMid:19156573

8. Luttikhuis HO, Baur L, Jansen H, Shrewsbury VA, O'Malley C, Stolk RP, et al. Interventions for treating obesity in children. Cochrane Database Syst Rev. 2009;(1):CD001872. https://doi. org/10.1002/14651858.cd001872.pub2

PMid:19160202 